Journal of Medical Education Development, 2017, Vol 10, No 27, 98 - 100

http://zums.ac.ir/edujournal/

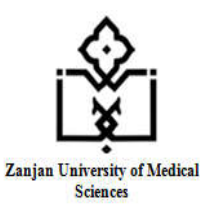

Letter to editor

\title{
Unequal Educational Opportunities Due to Gender Issues among Nursing Students
}

Fereshteh Araghian Mojarad ${ }^{1}$, Leila Jouybari ${ }^{2}$, Akram Sanagoo $^{3 *}$

\footnotetext{
${ }^{1}$ Student Research Committee, Golestan University of Medical Sciences, Gorgan, Iran.

${ }^{2}$ Medical Education Development Center, Golestan University of Medical Sciences, Gorgan, Iran.

${ }^{3}$ Nursing Research Center, Golestan University of Medical Sciences, Gorgan, Iran.
}

\section{Dear Editor}

While training in the school of nursing, students are faced with unequal educational situations in terms of gender. To clarify the issue, some of the experiences of nursing students and instructors have been discussed in this letter. In this regard, one of the male students remarked:

"We are not allowed to go to the maternity unit for practice. If someday I have to be in an emergency situation that requires care for a pregnant woman, I do not have the competency or adequate skills. Male medical students have practical training in maternity units, but we do not!",

In addition, a clinical instructor stated:

"Most of our clients in the community health nursing centers are women or young children with their mothers. I have sincerely tried to make paired groups of male and female nursing students, so that male students could participate in the care provision for mothers. We always obtain their permission before performing any procedures on female clients, asking them whether or not they would like a male student to be their nurse and carry out processes such as measuring their blood pressure and weight or offering them education on prenatal care."

However, neither female clients nor the healthcare providers and male students are interested in engaging in such situations. In general, male students believe that they are not able to work with mothers due to gender

*Corresponding author: Akram Sanagoo, Email:sanagoo@goums.ac.ir

This article is referenced as follows: Sanagoo A, Araghian Majarad F, Jouybari L. Unequal Educational Opportunities Due to Gender Issues among Nursing Students. J Med Educ Dev. 2018; 10 (27) :85-87 
difference. On the other hand, healthcare providers, especially midwives, consider care provision as a career of choice by women and are not willing to involve male students in these procedures.

Gender stereotypes remain a noticeable issue in the nursing profession and various other clinical services, and most male nursing students experience significant challenges in performing certain care procedures; such examples are the poor acceptance by patients and fear of the factors affecting their masculinity (1). Due to the key role of men in professional development and gender-based care, the policy of attracting and retaining men in the nursing profession should be further enhanced and emphasized.

Although the number of men recruited in the nursing profession has increased, more male nurses tend to leave their job compared to female nurses (2). In addition, male nursing students cannot receive certain trainings or enroll in specific clinical situations (3). Overall, male nurses experience significant professional barriers during their education and employment. Some of these barriers include the sense of isolation, gender stereotypes and inequality, and femaleoriented curriculum (4). Evidently, male and female students have different learning experiences in the field of nursing (3).

In a study in this regard, Marzoughi et al. concluded that improving educational justice could reduce job burnout, emotional exhaustion, educational apathy, and educational inefficiency (5). Considering the current statistics on the prevalence of gender inequality in the nursing profession, it is recommended that nursing schools provide equal learning opportunities for the male and female students (3).

Educational justice denotes the provision of equal educational opportunities for students, as well as equity in the encounters of educators with students, particularly in the classes where there are diversities among the students (6). In order to achieve educational equity, managers of educational institutions should change the structures and elements that contribute to educational injustice. One of the most important factors in this regard is the educators' behaviors and beliefs. Training courses could be implemented to adjust the attitudes and performance of educators, which in turn results in educational equality and justice (5).

Gender discrimination is defined as any distinction, exclusion or limitation instilled by social structures, norms, expectations, and gender roles (3). Cultural codes about the 
roles, responsibilities, and functions of men and women dictate the types of behaviors that are generally acceptable. Gender-dominated occupations are associated with numerous challenges, and employees are expected to behave in accordance with the dominate view of the society toward them and occupation. Seemingly, the nursing profession has been largely influenced by this issue compared to other professions (7). For instance, male nursing students are currently excluded from the practical trainings on maternity care, which could adversely affect their performance, especially in emergency situations.

It is recommended that qualitative studies be conducted on the male nursing students who experience sexism in order to improve the nursing educational curriculum, provide complementary training for the male students to acquire the necessary skills and clinical competency, and recruiting male counselors for male nursing students.

\section{References}

1- Chan ZC, Chan YT, Lui CW, Yu HZ, Law YF, Cheung KL, et al. Gender differences in the academic and clinical performances of undergraduate nursing students: a systematic review. Nurse Educ Today. 2014; 34(3):377-88.
2- Chou MH, Lee LC. Initial formation of nursing philosophies following fundamental clinical practice: the experience of male nursing students. J Nurs Res. 2007; 15(2): 127- 36.

3- Cottingham, J, Fonn, S, Garcia-Moreno, C, Gruskin, S, Klugman, B, Ndeto Mwau, A, et al. Transforming Health Systems: Gender and Rights in Reproductive Health. 2001. Available Online: http://www.who.int/reproductive health/publications/transforming_healthsystems_g ender/text.pdf. (Access date: July 20, 2016).

4- Zamanzadeh V, Valizadeh L, Negarandeh R, Monadi M, Azadi A. Factors Influencing Men Entering the Nursing Profession, and Understanding the Challenges Faced by Them: Iranian and Developed Countries' Perspectives. Nurs Midwifery Stud. 2013; 2(4): 49-56.

5- Marzoghi R, Haydari M, Haydari E. The Relationship between Educational Equity and Academic Burnout Welfare and Rehabilitation Sciences University. Strides Dev Med Educ. 2014; 10(3):328-334 [Persian].

6- Mosher LD. Critical Reflection, Educational Justice, and Teacher Formation in a Rural Setting. Doctoral dissertation. University of Redlands 2010. Available from: http://proquest.umi.com 7- Chou MH, Lee LC. Initial formation of nursing philosophies following fundamental clinical practice: the experience of male nursing students. J Nurs Res. 2007; 15(2): 127- 36. 